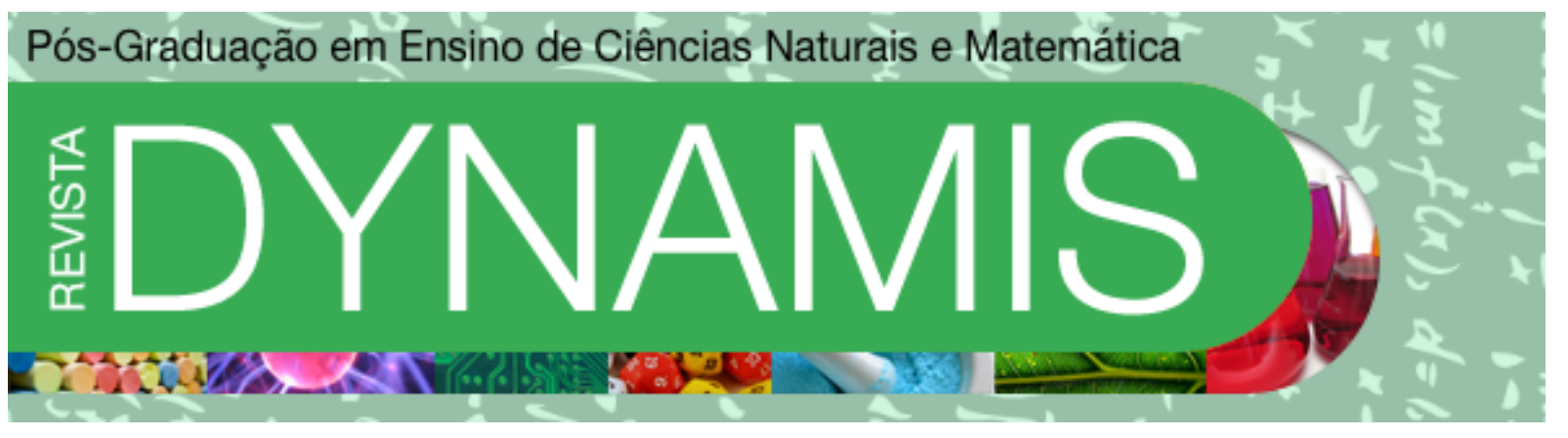

\title{
A TRANSDISCIPLINARIDADE NA FORMAÇÃO INICIAL DE PROFESSORES
}

The Transdisciplinarity in the Initial Teacher Training

Vera Lúcia de Souza e Silva

Universidade Regional de Blumenau - FURB - PPGECIM

verass@furb.br 


\section{Resumo}

O objetivo deste trabalho foi investigar as contribuições de uma proposta metodológica, baseada na ecoformação e na transdisciplinaridade, para a formação inicial de professores. Trata-se de uma proposta baseada em práticas educativas ecoformativas e transdisciplinares, numa visão inovadora de formação que qualifica para a vida. Além de discutir uma experiência pontual de formação inicial de professores numa visão transformadora, em direção à EDHEscola de Desenvolvimento Humano (Torre; Pujól \& Silva, 2013) este estudo delimita situações relevantes que podem contribuir para repensar a formação de professores, apontando alcance e limites da transdisciplinaridade neste processo. Trata-se de uma pesquisa de abordagem qualitativa realizada com 36 alunos do curso de pedagogia de uma Universidade Pública de SC, baseando-se na etnometodologia (Macedo, 2006) como metodologia do social baseada no interesse em descortinar as significações geradas pelos agentes sociais de uma dada realidade. A coleta de dados foi feita por meio de filmagens das aulas, que posteriormente foram transcritos e avaliados, além do uso da técnica de grupo focal (quatro grupos com nove pessoas) com estudantes sujeitos da pesquisa para posterior análise dos dados. Além disso, houve registro das produções dos alunos, concretizadas na forma de portfólios, modelos, textos, depoimentos durante o processo pedagógico e entrevista semiestruturada com os estudantes ao final do semestre letivo. Faz-se claro que as contribuições da ecoformação e da transdisciplinaridade para a formação inicial de professores assentaram-se em alguns principios da complexidade, tais como: complementaridade dos opostos, contextualização dos conteúdos, dialógico, recursão organizacional, flexibilidade e aceitação das diversidades e integração dos conteúdos.

Palavras-chave: Formação de professores; Ensino de ciências; Transdisciplinaridade.

\section{Abstract}

The aim of this study was to investigate the contributions of a methodology based on ecoformation and transdisciplinarity for initial teacher training. This is a proposal based on ecoformative and transdisciplinary educational practices and an innovative vision of training to qualify for life. Besides discussing a specific experience at initial teacher education, in a transformative vision toward School of Human Development ( Tower ; Pujol \& Silva , 2013 ), this study defines relevant situations that can contribute to rethinking teacher education, enhancing range and limits of transdisciplinarity in this process. This is a qualitative study held with 36 students of teacher training course from a public university at SC-Brazil, based on ethnomethodology (Macedo, 2006), as a social the methodology interested in unveiling out the meanings generated by the agents of a given social reality. Data collection was done by means of videotaping classes, which were later transcribed and evaluated, and the use of focus group technique ( four groups of nine people ) with students, research subjects, for further data analysis. Furthermore, students' productions were recorder in the form of portfolios, models, texts, depositions during the pedagogical process and semistructured interviews with students at the end of the semester. It is clear that the contributions of eco-formation and transdisciplinarity for initial teacher training and based on some principles of complexity, such as complementarity of opposites, contextualization of content, dialogical principle, recursion organizational (retroactive loop), flexibility and acceptance of diversity and integration of contents.

Keywods: Teacher training; Sciences teaching; Transdisciplinarity. 


\section{Introdução}

Refletir sobre a Educação nos remete a pensar a prática de formação de professores para que possamos contribuir para a emergência de modos alternativos e efetivos de pensar, agir e sentir. Por mais que fazemos e refletimos, ainda persistem deficiências e limitações, diante das dificuldades e provocações que a formação de professores nos traz diariamente.

$\mathrm{Na}$ Universidade muito dizemos, pesquisamos e publicamos, mas pouco percebemos em termos de melhorias nos processos de aprender e ensinar na Educação Básica. Por vezes, o excesso de discursos esconde uma pobreza das práticas educativas nas escolas, e raramente conseguimos fazer o que defendemos, criando um fosso entre o que se diz e o que se faz. É evidente, em nosso cotidiano, o círculo vicioso que se estabelece entre a formação inicial de professores mal qualificados e sua limitada atuação como profissionais nas escolas. Portanto, é preciso fazer um esforço para construir propostas educativas que nos façam sair deste círculo vicioso e nos ajudem a definir o futuro da formação de professores (Nóvoa, 2009).

A transdisciplinaridade e a ecoformação (Moraes, 2008; Nicolescu, 1999; Santos \& Sommerman, 2009; Silva, 2004; Torre, 2008; Torre; Zwierewicz \& Furlanetto, 2011; Torre, Pujól \& Silva, 2013) podem se apresentar como uma referência para a formação de professores, e servir de ponte entre práticas educativas tradicionais e inovadoras na formação de professores em busca de uma escola humanizadora, criativa e centrada em processos que visem o bem-estar das pessoas, da sociedade e da natureza. Esta pode se apresentar como uma possibilidade de formação de professores que supere a fragmentação e a descontextualização, mais conectada com a realidade complexa da escola e da sociedade.

Algumas pesquisas discutem o ensino de ciências levantando questões a respeito da formação de professores (Pozo \& Crespo, 2009; Delizoicov; Angotti \& Pernambuco, 2011 e Ward et al., 2010). Outras pesquisas apontam para a necessidade de possibilitar que os estudantes percebam a Ciência como algo relacionado à vida cotidiana e como um processo histórico (Chassot, 2011; Demo, 2010; Freire \& Macedo, 1990). A formação inicial de professores pode contribuir para o ensino de Ciências inovador, numa abordagem transdisciplinar do conhecimento. Uma das características da transdisciplinaridade é a integração não só do desenvolvimento de tecnologias em função da humanidade, mas também, de buscar conhecimentos que harmonizem esta relação, conforme Guevara et al. (1998, p. 13) "o ser humano procura se entender não só como uma realidade em si, como um indivíduo, mas igualmente no seu relacionamento com outros, como uma realidade social."

O objetivo deste trabalho foi investigar as contribuições de uma proposta metodológica, baseada na ecoformação e na transdisciplinaridade, numa turma de Pedagogia, na disciplina de biologia humana, de uma Universidade Pública do Estado de Santa Catarina. Esta disciplina tem o objetivo de reconhecer a natureza biológica e sistêmica do ser humano e as relações com a aprendizagem do autocuidado para a promoção da saúde integral em espaços de aprender.

Os pressupostos teórico-metodológicos da ecoformação e da transdisciplinaridade, que nortearam a proposta da disciplina, serviram de referência para reconhecer a importância da auto e da heteroformação para a manutenção da dinâmica da vida pessoal e profissional dos estudantes. Destaca ainda a necessidade de dimensionar e refletir as questões relacionadas à promoção de vida saudável do professor e dos estudantes. Esta visão procura se fundamentar em processos que envolvem transformações nos hábitos e atitudes, que requerem do profissional docente um maior compromisso e responsabilidade com os processos educativos, a partir de uma consciência transdisciplinar da vida e do ato de educar e educar-se. Esta é uma proposta que se apresenta como um caminho que está sendo trilhado para a formação que 
qualifica para a vida, baseada em práticas educativas contextualizadas na vida saudável. Assim, além de discutir uma experiência pontual de formação inicial de professores numa visão transformadora, delimita situações relevantes que podem contribuir para repensar a formação de formadores.

É uma proposta baseada em práticas educativas ecoformativas e transdisciplinares, numa visão inovadora de formação que qualifica para a vida. Além de discutir uma experiência pontual de formação inicial de professores numa visão transformadora, em direção à EDH- Escola de Desenvolvimento Humano (Torre; Pujól \& Silva, 2013), este estudo delimita situações relevantes que podem contribuir para repensar a formação de professores, apontando alcance e limites da transdisciplinaridade neste processo. Pode ainda, contribuir para o despertar da consciência diante dos padrões e percepção sobre a realidade, do sentido da vida e do ser humano nesse universo planetário que nos toca viver (Torre; Zwierewicz \& Furnaletto, 2011).

\section{Revisão da Literatura}

Para Santos e Sommerman (2009) investigar os aspectos relevantes de uma teoria pedagógica fundamentada na transdisciplinaridade é buscar novos aportes à questão do processo de ensino, e, embasados nos fundamentos de que trata essa postura, fundamentar-se nos princípios de uma visão crítica. Somente poderemos favorecer mudanças no processo de ensino e de aprendizagem, ou seja, no modo de ensinar, se tivermos uma nova perspectiva do pensar, numa outra postura epistemológica. A transdisciplinaridade importa transgressão das fronteiras epistemológicas, por isso mesmo requer dos docentes atitudes transversáteis e sua atuação nos diferentes níveis do real, tanto na dimensão dos opostos como no nível da articulação e do diálogo entre saberes (Santos \& Sommerman, 2009, p. 68).

A escola do século XXI necessita que o professor deixe de ser meramente um transmissor de conhecimentos. Uma das preocupações do ensino de Ciências atualmente passou a ser a de oferecer condições para que o estudante identifique problemas a partir de observações, análises, discussões, sendo capaz de opinar e estabelecer relações com os fatos, trabalhando de forma a inferir conclusões a partir de suas próprias observações.

Atualmente, busca-se para o ensino de Ciências reflexões que incluam temas transversais relativos à saúde e ao ambiente, pois de acordo com os Parâmetros Curriculares Nacionais de Ciências Naturais - PCN um dos objetivos que rege o ensino de Ciências é "compreender o corpo humano como um todo integrado e a saúde como bem-estar físico, social e psíquico do indivíduo" (Brasil, 1997, p. 84). Estas diretrizes podem nortear práticas educativas em ambientes de aprendizagem que incentivem problematizações dos conteúdos e discussões em sala de aula, que preveem uma maior integração entre a Ciência e a Sociedade. Além disso, podem também favorecer uma revisão na abordagem dos conteúdos explorados nas aulas de Ciências, pelo papel fundamental desta área do conhecimento na construção de uma cidadania plena, oportunizando o desenvolvimento da autonomia dos estudantes na direção de escolhas mais saudáveis no seu cotidiano.

É importante destacar que, segundo os PCN (Brasil, 1997, p. 35) "no planejamento e no desenvolvimento dos temas de Ciências em sala de aula, cada uma das dimensões dos conteúdos deve ser explicitamente tratada". Pois é fundamental que o estudante compreenda que a cidadania acontece a partir de sua participação de maneira crítica e construtiva nos planos social, cultura e político da sociedade, no cumprimento de direitos e deveres. Para a formação da cidadania, o conhecimento científico contribui para que o estudante possa ter um espaço de informações sobre o mundo, sobre os fenômenos da natureza, sobre as transformações que ocorrem diariamente, e, onde ele possa se expressar de forma dinâmica. 
Lorenzetti e Delizoicov (2001) defendem o pressuposto de que o ensino de Ciências pode ser um forte aliado para a aquisição de leitura e escrita, uma vez que contribui para atribuir significado às palavras e aos discursos. E a partir da linguagem da Ciência, com seus significados e códigos, é possível a construção da cidadania, de autonomia que visam escolhas mais conscientes e críticas no mundo em que vivemos.

Ensinar Ciências significa modificar o processo de compreensão do mundo a partir da troca de ideias e reflexões com outras pessoas e grupos, conforme discutido por Gutiérrez e Prado (2002, p. 71) como "uma educação que não passa pela constante e rica expressão de seus interlocutores continua mergulhada no pântano dos velhos moldes da resposta esperada e dos objetivos sem sentido como se assinala na mediação."

É preciso aproximar conteúdos aprendidos na escola do contexto vivido pelo estudante, levando uma proposta que contextualize os conteúdos científicos estudados na escola. Com isso, o ensino de Ciências pode favorecer a aproximação entre o saber do senso comum e o saber científico, trazendo mais sentido aos conteúdos aprendidos ao relacioná-los com a vida dos estudantes. Nesta direção, a ecoformação pode ser uma grande aliada do ensino de Ciências ao oportunizar a abordagem de conteúdos do cotidiano com vistas a relacioná-los aos científicos, tais como: cuidados com o corpo, alimentação, exercícios físicos, sono, diminuição do stress, lazer, relações interpessoais, sustentabilidade entre outros.

A ecoformação possui algumas características a serem consideradas: a) vínculos interativos com o entorno natural e social, pessoal e transpessoal; b) desenvolvimento humano a partir de e para a vida, em todos os seus âmbitos de maneira sustentável ; c) caráter sistêmico e relacional que nos permite entender a formação como redes relacionais e campos de aprendizagem; d) caráter flexível e integrador das aprendizagens ; e) princípios e valores de meio ambiente que consideram a Terra como um ser vivo, onde convergem os elementos da natureza tanto vivos como inertes (Torre, 2008, p. 21).

Sabemos que a formação inicial de professores passa por uma discussão profunda e abrangente por vários aspectos de extrema importância e que estão relacionados à necessidade de uma revisão significativa nos sistemas educacionais. Fundamentado na abordagem transdisciplinar (Antônio, 2002; Moraes, 2008; Nicolescu, 1999; Torre, 2008; Torre, Zwierewicz \& Furlanetto, 2011; Silva, 2004; Santos \& Sommerman, 2009; Weil; D’Ambrosio \& Crema, 1993) podemos colaborar para um repensar de práticas educativas mais articuladas, integradoras e voltadas para a criatividade e, acima de tudo, para o conhecimento que aponte com sentido para a vida.

\section{Metodologia}

Trata-se de uma pesquisa de abordagem qualitativa, baseando-se na etnometodologia (Macedo, 2006), como metodologia do social baseada no interesse em descortinar as significações geradas pelos agentes sociais de uma dada realidade. "Quais as contribuições de uma prática educativa baseada na abordagem transdisciplinar para a formação inicial de pedagogos/as?" foi a questão de pesquisa investigada. Esta experiência foi vivenciada nas aulas da disciplina de biologia humana, com 36 estudantes da primeira fase do curso de Pedagogia, da Universidade Regional de Blumenau (FURB/SC), no período de fevereiro a maio de 2013, num total de 50h/a. Esta pesquisa é um recorte de uma pesquisa que se estende desde 2004, em dez turmas de pedagogia desta Universidade, na disciplina de biologia humana.

O objetivo geral foi investigar as contribuições da proposta metodológica baseada na ecoformação e na transdisciplinaridade no processo de formação inicial de professores. Os 
procedimentos metodológicos serão apresentados em duas etapas neste texto, compreendidas em metodologia das aulas e metodologia da pesquisa.

Procedimentos metodológicos das aulas: o tema desenvolvido na disciplina de biologia humana foi "Respeitar e Cuidar do Corpo e do Meio", na perspectiva da ecoformação e da transdisciplinaridade. As aulas foram organizadas de forma a colaborar com o alcance dos objetivos do curso de Pedagogia, que se fundamenta em formar profissionais com base teórico-prática que permita a reflexão crítica, a autonomia intelectual e atuação profissional, comprometida com um processo educativo democrático e libertador. Os conteúdos da disciplina selecionados para trabalhar a formação inicial de professores nesta abordagem foram: Fundamentos teórico-metodológicos da ecoformação e transdisciplinaridade na biologia humana; Escola do século XXI: uma escola criativa e transformadora; Projetos Criativos Ecoformadores (PCE): conceitos e práticas; Elaboração e apresentação de um PCE para anos iniciais do ensino fundamental com o tema: Saúde Integral- respeitar e cuidar do corpo e do meio.

Um PCE "representa um referencial de ensino e de aprendizagem baseado na autonomia, na transformação, na colaboração e na busca do desenvolvimento integral da pessoa" (Torre \& Zwierewicz, p.153, 2011). Os projetos elaborados nas aulas de BH partiram dos interesses dos alunos e procuraram estabelecer relação com os conteúdos da ementa da disciplina. Além disso, buscaram promover atitudes colaborativas, pois foram feitos em equipes de até 4 integrantes, e por isso exigiu certa flexibilidade dos estudantes, considerando as necessidades que surgiram durante o seu desenvolvimento.

As metodologias utilizadas nas aulas foram baseadas nos princípios de ecoformação e transdisciplinaridade entre elas: autobiografia dos estudantes (narrativas de trajetória da vida escolar); vídeos (com roteiros de estudos); palestras de especialistas nas áreas do estudo (com roteiros de estudo); textos e artigos nas áreas; dinâmicas de grupo; relaxamento e visualização criativa; visitas orientadas a instituições de ensino da educação básica da região com propostas inovadoras; elaboração e apresentação de um PCE (Projeto Criativo Ecoformador metodologia transdisciplinar) para os anos iniciais da educação básica.

Usamos o Portfólio como forma de registro e avaliação do processo. Segundo Hernández (1998), o portfólio é continente de diferentes classes de documentos, tais como: notas pessoais, experiências de aula, trabalhos pontuais, acompanhamento do processo de aprendizagem, conexões com outros temas estudados fora da escola, representações visuais, dentre outros registros. Estes proporcionam uma reflexão crítica do conhecimento construído, das estratégias utilizadas, e da disposição de quem o elabora em continuar aprendendo. $\mathrm{O}$ Portfólio constitui uma forma de avaliação dinâmica realizada pelo próprio aluno e que mostra seu desenvolvimento e suas mudanças através do tempo.

Sá-Chaves (2000) aponta que o uso do portfólio contribui para:

- promover o desenvolvimento reflexivo dos participantes da aprendizagem;

- estimular o processo de elaboração conceitual nas questões pertinentes à docência;

- fundamentar os processos de reflexão para a ação na docência;

- incentivar a autonomia, a originalidade e a criatividade individuais no que se refere aos processos de intervenção educativa;

- organizar um material para consulta do futuro professor;

- facilitar os processos de (auto) avaliação da aprendizagem.

O conteúdo do portfólio foi organizado por encontro, constando: anotações da aula; textos recomendados para leitura; trabalhos recomendados pelos professores; reflexões e comentários sobre os temas abordados em aula; dicas de sites ou referências, outros textos, 
imagens, técnicas de ensino, depoimentos e outros documentos sobre o tema de estudo dos encontros. Os critérios de avaliação (auto e hetero-avaliação) foram: presença de registros sistematizados com reflexões a respeito de: anotações da aula, textos, tarefas, complementos, sínteses, comentários; organização e rigor na apresentação e originalidade e criatividade na elaboração do portfólio. Estes portfólios foram utilizados como forma de avaliação e acompanhamento das atividades realizadas na disciplina e neste relato de experiência.

A (auto) organização é um fenômeno que ocorre naturalmente, como apontam Maturana e Varela (2010) ao criar o termo autopoiese. Para os autores, um sistema é autopoiético quando é constituído por um conjunto de componentes cujas transformações e interações não cessam de reproduzir a organização a qual pertencem. Assim, a própria vida deve ser entendida como um processo de conhecimento, cuja finalidade é proporcionar ao organismo os meios para que ele se adapte para sobreviver. E é no coletivo que aprendemos com maior eficiência e rapidez.

O mundo se organiza para encontrar a própria eficácia, e assim o fazem as pessoas com possibilidades de realizar algo no coletivo. Isso pode ser efetivado na formação de professores, para exercitar a partilha desde a formação inicial. Para Wheatley (2006), a verdadeira organização acontece quando as pessoas veem o que precisa acontecer, aplicam sua experiência e sua percepção à questão, descobrem quem pode ajudá-las e usam a própria criatividade para inventar soluções. As soluções aparecem como manifestação da criatividade que emerge de processos de incentivo e acolhimento do outro, no seu processo de conhecer e viver. Os resultados são mais ricos e amplos no movimento do coletivo. Mas estaremos mais conectados ao outro, se nos conectarmos a nós mesmos. Estarmos conectados a nós mesmos para então nos conectarmos ao outro é passo fundamental para promover a intimidade entre as pessoas (Silva, 2004).

As aulas foram pautadas numa educação centrada na vida, fundamentada na construção coletiva e colaborativa de experiências e saberes. Onde, o essencial é o diálogo existente entre todos os campos do conhecimento científico, partindo das relações entre os indivíduos e destes com o ambiente, através da cultura e dos saberes de cada comunidade. Para Bonil e Calfell (2008) este diálogo disciplinar permite dialogar entre os saberes disciplinares a partir de uma visão que foge do reducionismo e das relações hierárquicas entre disciplinas, em que cada um reconhece seus limites para se aproximar dos fenômenos do mundo. O foco é colaborar para a construção do perfil de professor que promova uma educação para a ampliação da consciência individual, social e planetária para a formação do cidadão para uma vida plena em sociedade. Vale considerar que ensinamos aquilo que somos e que, naquilo que somos se encontra muito daquilo que ensinamos (Nóvoa, 2009).

De acordo com os objetivos propostos, observamos as atividades realizadas em sala de aula, refletindo as questões de estudo, oportunizando e estimulando discussões para que os estudantes percebessem o papel da transdisciplinaridade e da ecoformação na sua formação inicial como professores da educação básica. Desta forma, entendemos que aprender Ciências, a partir da abordagem transdisciplinar e da ecoformação, pode contribuir para a formação de cidadãos mais críticos, humanizados, com possiblidades de fazer escolhas mais saudáveis para a sua vida e a vida no planeta.

Procedimentos metodológicos da pesquisa: a coleta de dados foi feita por meio de filmagens das aulas, que posteriormente foram transcritas e avaliadas, além do uso da técnica de grupo focal (quatro grupos com nove pessoas) com estudantes sujeitos da pesquisa para coleta e análise dos dados. Como técnica de pesquisa qualitativa, o grupo focal tem sido utilizado internacionalmente para o planejamento de atividades educativas, como objeto de promoção em saúde e meio ambiente; podendo ser utilizado também para a revisão do 26 
processo de ensino-aprendizagem (Lervolino \& Pelicione, 2001; Backes et al, 2011). Nesta metodologia, os grupos tiveram duração máxima de 1 hora, e foram conduzidos por um moderador que seguiu um roteiro previamente estabelecido, composto de elementos, tais como: de percepção dos estudantes em relação aos cuidados com a sua saúde e do meio; desenvolvimento de atividades de educação em saúde na educação básica; práticas educativas relacionadas à promoção de cuidados com a saúde de professores e alunos; desenvolvimento das atividades da disciplina de biologia humana para o cumprimento dos objetivos propostos e contribuições da abordagem da ecoformação e transdisciplinaridade para a formação inicial de professores. Esse roteiro foi preparado a partir dos objetivos do estudo, propondo a discussão do tema e mantendo o grupo focalizado pelo tempo julgado necessário pelo moderador. Com a permissão dos participantes, os grupos foram filmados e gravados. Os dados foram posteriormente transcritos, permitindo a avaliação qualitativa dos dados.

Além disso, houve registro das produções dos alunos, concretizadas na forma de portfólios, modelos, textos, depoimentos durante o processo pedagógico e entrevista semiestruturada com os estudantes ao final do semestre letivo. O objetivo das variadas formas de coleta e registros de dados foi ampliar a investigação sobre as contribuições da proposta metodológica baseada na ecoformação e na transdisciplinaridade no processo de formação dos estudantes de pedagogia, futuros professores. Estes registros, feitos sistematicamente, serviram ainda como referência de (auto) avaliação do processo e como instrumento de aprendizagem de ser professor, pois entendemos que "quem tem o hábito de refletir sobre suas próprias experiências, examinando amostras de seus trabalhos e repensando seu progresso como escritores, pesquisadores, experimentadores e artistas, gradualmente aprendem a definir objetivos de aprendizagem por si mesmos" (Shores \& Grace, 2001).

Como procedimento de análise dos grupos focais, utilizamos o sumário etnográfico, técnica que se detém nas citações textuais dos participantes do grupo, que vão assim ilustrar os achados principais da análise (Lervolino \& Pelicione, 2001). Além disso, houve a descrição e interpretação dos resultados apresentados durante o processo, contidos nos documentos de registros e nas falas dos trinta e seis sujeitos, denominados Estudante de 01 a 36 (E1, E2, E3...). As categorias de análise definidas posteriormente à coleta de dados foram estabelecidas de acordo com os princípios da ecoformação e transdisciplinaridade pesquisados e abordados nas aulas. A seguir apresentaremos as discussões dos resultados, a partir da análise dos dados coletados nesta experiência, confrontados com os eixos teórico/metodológicos norteadores da proposta pedagógica da disciplina de biologia humana para a formação inicial de professores.

\section{Análise dos dados}

As reflexões sobre o processo educativo, a partir dos relatos nos grupos focais, assim como nos relatos escritos nos registros das aulas, leitura reflexiva dos portfólios, depoimentos, registros de atividades realizadas pelos estudantes do curso de Pedagogia constituíram-se num espaço de reflexão sobre as contribuições dos pressupostos da transdisciplinaridade e da ecoformação na formação inicial destes estudantes, futuros pedagogos e pedagogas.

Buscamos assim, verificar como esta abordagem contribuiu para a fundamentação de uma prática educacional na direção do que os autores Zwierewicz e Torre (2009) e Torre, Zwierewicz e Furlanetto (2011) apresentam, quando defendem que é preciso a compreensão de novos aportes teóricos que colaborem para uma leitura contextualizada de uma formação de professores construída a partir de uma abordagem inovadora. Os resultados da pesquisa sobre o processo ecoformador e transdisciplinar apontam para o reconhecimento pelos 
estudantes de alguns princípios que estruturaram esta abordagem, entre eles: complementaridade dos opostos, contextualização dos conteúdos, dialógico, recursão organizacional, flexibilidade e aceitação das diversidades e integração dos conteúdos.

Os princípios da complementaridade dos opostos e da contextualização dos conteúdos nos permitem integrar os fenômenos complexos que compreendem o objeto estudado. A complementaridade está intimamente relacionada a oferecer espaço nas aulas para a subjetividade, a emoção, a articulação dos saberes disciplinares aos contextos do que vivem os estudantes, ao mundo de suas vidas. No relato de E5, a ecoformação e a transdisciplinaridade "nos ajudam a olhar para dentro de nós mesmos, [...], abrindo nossos horizontes, de nossa mente e os sentimentos que fluem do nosso ser". Ainda na direção da contextualização, percebemos no depoimento de E3, que tanto a ecoformação como a transdisciplinaridade "são importantes para nossa formação para aprendermos a ver o novo, a sair de todo um contexto já usado, a usarmos novos métodos, a usar a criatividade; aprendermos a olhar o outro, olhar o meio em que vivemos e principalmente a olharmos para nós mesmos".

Percebemos a contextualização como um avanço nas aulas de biologia humana, que aponta na direção do que afirmam Santos e Sommerman (2009) sobre práticas inovadoras transdisciplinares, que nesse novo referencial representa uma mudança epistemológica, e vem sugerindo reconceitualizações de categorias analíticas, em que houve a supervalorização da objetividade e racionalidade, como também da descontextualização, simplificação e redução quando o fenômeno é complexo. As realidades objetivas e subjetivas são complexas e interativas.

Porém, quando o professor desconsidera a dinâmica interativa, ele prioriza determinado conteúdo e recorre ao processo de memorização para o processo de aprender. Isso não oferece espaço em suas aulas para a subjetividade e a contextualização de saberes. Para o estudante E13, "a ecoformação e a transdisciplinaridade em nossa formação como pedagogos contribuem para o desenvolvimento pessoal, fazendo-nos refletir sobre nossas próprias atitudes. Como consequência, seríamos professores transformadores, visando sempre o cuidado com o corpo, a natureza e a criatividade”. Para Santos e Sommerman (2009) transformar o conhecimento num ato de afirmação do ser é o desafio que se coloca na reconstrução da prática pedagógica.

O princípio dialógico é a associação complexa, que une dois princípios ou noções que deveriam excluir-se reciprocamente, mas são indissociáveis em uma mesma realidade, pois são complementares (Morin, 2000). Desta forma, o pensamento complexo assume dialogicamente dois termos que tendem a se excluir um ao outro, neste caso: conteúdos trabalhados na disciplina biologia humana e princípios teórico-metodológicos da ecoformação e da transdisciplinaridade. Para Sousa Santos (2008) o conhecimento universitário foi ao longo do séc. XX, um conhecimento predominantemente disciplinar. Assim, a fragmentação dos saberes dos conteúdos curriculares, fruto da excessiva especialização e da concepção tecnológica positivista, acaba por tornar estes saberes desarticulados, sem expressão de significados de interdependência e sem visão de conjunto que favorece a aprendizagem.

Apoiados em Morin (2000), percebemos que o princípio dialógico colaborou para integrar os múltiplos dados e ângulos na abordagem do tema corpo humano e relações com o meio ambiente. Ainda segundo o autor, esse sistema de pensamento busca reintegrar o que a compartimentação das disciplinas científicas fragmentou e dividiu em especialidades separadas, e, em muitos casos, praticamente incomunicáveis. 
A recursão organizacional evoca o sentido de círculo gerador, em que os produtos e os efeitos são eles mesmos, produtores e causadores daquilo que os produz. Nos sistemas autopoiéticos (Mariotti, 2000) afirma que o produto é também o produtor, ou seja, num dado momento não se pode fazer a diferença entre o que produz, o que é produzido e a produção. Assim, nós seres humanos somos produtores da sociedade em que vivemos e ela nos produz como seres humanos em e pelas suas interações, trazendo a cultura e a linguagem. Este princípio amplia a ideia simplista de sequencias lineares de tipo causa-efeito, e abre a nossa compreensão para a complexidade dos fenômenos naturais (Mariotti, 2000). Nas aulas de BH consideramos que a ação do professor incentivador pode colaborar recursivamente para ações mais empreendedoras dos alunos, colaborando positivamente no processo de construção e reconstrução de saberes. Para o E3: "Aprender pode ser prazeroso e motivador, mas depende muito da ação do professor." Sabemos que o reforço positivo do professor diante de resultados positivos no ato de aprender ciências, facilita o aprendizado e oportuniza avanços do saber dos estudantes. No processo de aprender BH, estudantes e professor se apresentam como atores/produtores da mesma peça, num mesmo palco para a promoção da saúde integral. Isto é realizado num movimento pedagógico e didático de aprender a respeitar e cuidar do corpo, direcionados nas aulas a refletirem sobre: qual a atenção dada ao seu próprio corpo? As aulas favorecem o contato do aluno com seu próprio corpo? Há atividades de percepção do corpo e de suas necessidades?

A atitude transdisciplinar é uma atitude flexível, pois "busca a compreensão da complexidade de nosso universo, da complexidade das relações entre sujeitos, dos sujeitos consigo mesmos e com os objetos que os circundam, a fim de recuperar os sentidos da relação enigmática do ser humano com a Realidade", pautada no documento final do II Congresso Mundial de Transdisciplinaridade (Mensagem de Vila Velha e Vitória, 2005). Ser flexível, nesta construção transdisciplinar do conhecimento, é necessário para poder considerar a complementaridade entre saberes e diferenças humanas, que requerem uma autotransformação, mudança de percepção, de olhar, de atitude e de comportamento. Esta atitude esteve presente nesta experiência, na fala de E1 que afirma que transdisciplinaridade “...forma pensamentos e vários pontos de vista. É quando podemos ser dinâmicos enquanto professores". Um registro no portfólio de E9 indica que "para a formação de pedagogos a transdisciplinaridade é muito importante... mas para que aconteça, as primeiras atitudes tem que ser nossas, sendo flexiveis e buscando sempre a mudança e a transformação". Para E2, a ecoformação "é a relação que o indivíduo tem consigo mesmo e com o meio em que vive. Já a transdisciplinaridade traz uma nova visão (...), interligando as disciplinas". Esta concepção revela o que se deseja ao trabalhar conceitos e práticas transdisciplinares, uma atitude de ampliação da compreensão da diversidade do modo de pensar, mais amplo e aberto, ampliando horizontes e relativizando o que era concebido como verdade única e indiscutível. Aceitar outros olhares como outras possiblidades de verdades que se complementam, vai ao encontro do que nos apresentam Santos e Sommerman (2009), ao defenderem que essa aceitação nos conscientiza dos mitos e do caráter particular de muitos valores que julgávamos universalistas, permitindo-nos descobrir o que realmente eles têm de universais.

A integração de conteúdos e práticas educacionais foi revelada nos depoimentos dos participantes dos grupos focais e nos portfólios dos estudantes. No registro de seu relatório de visita à escolas, o E1 aponta: "a disciplina de Biologia Humana fez com que além de pensar no corpo do aluno eu consiga pensar nele como um ser, como um todo, não esquecendo que ele também tem sentimentos que precisam ser trabalhados". O estudo do tema Visão Sistêmica do ser humano, enfocou a necessidade de relacionar os aspectos biológicos aos aspectos psico-sociais-ambientais nas relações corpo-mente, como elementos indissociáveis na constituição do ser humano. Isto se revela no depoimento do estudante ao reconhecer a 
natureza sistêmica do ser humano e as relações com a aprendizagem do autocuidado para a promoção da saúde integral.

Uma das categorias de análise do estudo apontou a construção de saberes de forma articulada da biologia humana com outras disciplinas do curso, tais como: psicomotricidade, psicologia e estágio supervisionado. Nóvoa (2009) nos convoca a refletir sobre a necessidade do trabalho em equipe, os novos modos de profissionalização docente implicam um reforço das dimensões coletivas e colaborativas, do trabalho em equipe, da intervenção conjunta nos projetos educativos da escola.

Atividades e conteúdos das quatro disciplinas se entrelaçaram no entendimento de processos de ensinar e de aprender na educação básica, tais como: visão sistêmica do ser humano, promoção de saúde integral em espaços de aprender, aprendizagem do autocuidado, as relações humanas no processo educativo, a importância do relaxamento para o equilíbrio psicossomático; e observação, registro e análise de instituições educativas da região. Além disso, quatro visitas a escolas da região foram organizadas conjuntamente por estas disciplinas com o objetivo de permitir a leitura do movimento real do ensino fundamental e da educação infantil, bem como a construção de um referencial teóricometodológico para a ação docente a partir da realidade concreta (escola e centros de educação infantil).

Para estas visitas os estudantes foram orientados com roteiros de observação previamente elaborados, baseados em princípios de ecoformação e transdisciplinaridade, entre outros de ação educativa da pedagogia. Os conteúdos das visitas foram: A Instituição escolar: observação, registro e análise de processos e práticas edcucacionais; As relações socioambientais-culturais-afetivas da comunidade escolar. Os roteiros foram discutidos integradamente e serviram de estudo e reflexão para os estudantes após as visitas, orientados pelos professores das disciplinas. O pensamento complexo (Morin, 2000) pratica o entrelaçamento e se prolonga na busca da fluidez das fronteiras dos conteúdos. Assim, entendemos que o entrelaçamento ocorrido entre as disciplinas foi um efetivo facilitador para o entendimento de processos de aprender e ensinar na escola. Isto foi facilitado pela abordagem não mecanicista, menos linear e não fragmentada da abordagem utilizada em sala de aula pela biologia humana, favorecendo que os conteúdos científicos tenham tido expressão de significados de interdependência e com visão de conjunto.

Outra atividade realizada com os estudantes foi a aproximação com o Programa de ensino, pesquisa e extensão da FURB, a RIEC- Rede Internacional de Escolas Criativas que se baseia na interdisciplinaridade, transdisciplinaridade, complexidade e na ecoformação como princípios investigativos e formativos. O Programa da FURB faz parte da Red Internacional de Escuelas Creativas (RIEC), com atuação na Argentina, Bolívia, Brasil, Chile, Colômbia, Espanha, México, Peru e Portugal que, entre outras metas, pretende potencializar o estabelecimento de parceria investigativa em Rede e em cooperação Internacional, fundamentais para o desenvolvimento da pesquisa na FURB e no Brasil. A RIEC tem aprofundado as questões reflexivas acerca da ecoformação e transdisciplinaridade, na busca de formação inicial e continuada de professores, enfocando questões conceituais e metodológicas. Do mesmo modo, pesquisa e identifica iniciativas, ações e projetos criativos e inovadores em escolas da rede pública de ensino de Blumenau.

Porém, apesar das limitações que se apresentam aos professores no seu cotidiano profissional, tem-se verificado experiências exitosas relacionadas a práticas educativas de qualidade. Esta constatação está baseada em pesquisas realizadas pela RIEC FURB em escolas da região, entre elas a EBM Visconde de Taunay, reconhecida e diplomada, em maio/2013, pela RIEC como escola criativa. 
Com o objetivo de adotar práticas de sustentabilidade na escola, adaptando seus espaços e tempos, para sensibilizar alunos e famílias de que as mudanças no planeta começam em casa, na escola e na comunidade, a EBM Visconde de Taunay criou o Projeto "Escola Sustentável", em 2010. Após lerem e debaterem em aula sobre escolas criativas e sustentabilidade (Torre \& Zwierewicz, 2009), os estudantes de pedagogia visitaram a escola, leram e refletiram sobre seu Projeto Pedagógico, fizeram observações das aulas e dos projetos de sustentabilidade que serviram de referência para a elaboração de seus Projetos Criativos Ecoformadores durante o semestre letivo. Além disso, participaram de um encontro de formação intitulado "A formação do professor para uma escola criativa e transformadora", em maio/2013 na FURB, com o prof. Saturnino de la Torre da Universidade de Barcelona, mentor da RIEC.

Precisamos de uma formação que atue na abordagem da ecoformação que reeduque nossos estudantes, de uma educação para uma vida saudável e sustentável. A escola ecoformadora, de acordo com Torre, Zwierewicz e Furlanetto (2011) contribui para que o estudante esteja em um ambiente escolar em que ele se prepare para a vida, que tenha consciência de seus atos num ambiente em que ele transforme as situações do cotidiano em oportunidades para o seu bem-estar e para com o ambiente.

Esse aspecto aparece nas falas dos estudantes, como podemos analisar a seguir. E6 enfatiza a importância da ecoformação, numa das reflexões no seu portfólio, por "nos levar a entender o meio ambiente e interagir com ele e levar as crianças a respeitar esse meio e dar mais valor ao lugar. Ecoformação é fazer parte do meio". Também na fala de E7 num grupo focal, ao afirmar que "a formação de um pedagogo com perfil diferenciado a fim de atender às novas necessidades de inter-relação, preocupação ambiental e com o mesmo (com o eu)". E para E14 num dos relatórios da visitação à escolas, "a ecoformação trabalha o meio, os outros e a si próprio formando respeito ao meio ambiente, visando a sustentabilidade". No relatório final de E11, este deixa claro que na formação de professores é preciso uma visão de conhecimento com "um olhar panorâmico para si e ao seu redor, valorizando princípios, valores e todo o meio. Uma transformação para a construção do desenvolvimento humano com o meio em que vive e no meio ambiente escolar. Devemos buscar cenários transdisciplinares, ultrapassando o tradicional, inovar no modelo pedagógico". Outro depoimento revelado no portfólio de uma estudante: "Após visitar a escola Visconde de Taunay e fazer leitura do texto sobre escolas criativas, minha percepção sobre o que é criativadade e escola inovadora mudou completamente. O que antes era só um trabalho diferente, hoje vai muito além do ser, ela vem de dentro para fora e isto será levado por toda a minha vida." (E15).

Estes relatos demonstram a importância da inovação na prática educativa e a busca por estratégias que sejam estimuladoras da participação dos estudantes no processo de aprender, desafiando-os em situações problemas contextualizados. Para Moraes (2008, p. 226) "tudo isto nos revela que a docência transdisciplinar requer do educador uma atitude condizente com o seu grau de percepção e de consciência".

O (auto) conhecimento do professor pode colaborar para a ampliação do entendimento destas relações, como preconizado por Nóvoa:

Refiro-me à necessidade de elaborar um conhecimento pessoal (um autoconhecimento) no interior do conhecimento profissional e de captar (de capturar) o sentido de uma profissão que não cabe apenas numa matriz técnica ou científica. Toca-se aqui em qualquer coisa de indefinível, mas que está no cerne da identidade profissional docente. O registo escrito, tanto das vivências pessoais como das práticas profissionais, é essencial para que cada um adquira uma maior consciência do seu trabalho e da sua identidade como professor. A formação deve contribuir 
para criar nos futuros professores hábitos de reflexão e de auto-reflexão que são essenciais numa profissão que não se esgota em matrizes científicas ou mesmo pedagógicas, e que se define, inevitavelmente, a partir de referências pessoais. (Nóvoa, 2009, p.39)

Acreditamos, assim, que o aprendizado da auto-observação faz parte do aprendizado da capacidade do autoconhecimento e da (auto) crítica. Para Morin (2000), a aptidão reflexiva do espírito humano, que o torna capaz de considerar-se a si mesmo, ao se desdobrar, deveria ser encorajada e estimulada em todos. Além disso, é preciso considerar que se trata de um processo de aprender sobre si e sobre o mundo, pois além de nunca ser concluído, deve ser continuamente recomeçado.

\section{Conclusão}

As aulas de biologia humana desenvolvidas neste trabalho, contextualizadas e fundamentadas na abordagem transdisciplinar e ecoformadora, oportunizaram novos saberes para novos fazeres dos estudantes que estão se preparando para a docência na Educação Básica. Ao se fazer a religação dos saberes disciplinares, configura-se o que conhecemos como propriedades emergentes do conjunto. São percepções que se apresentam e possibilitam uma nova visão, que está como o prefixo trans nos aponta: entre, através e além...impossível de ser percebida sem a religação dos saberes. E isso requer que sejamos nós, professores, a mudança que desejamos para nossos estudantes. Este trabalho nos levou por caminhos entre, através e além dos caminhos tradicionais de educação e de formação inicial de professores. Somos colocados em marcha, caminhantes com o lema do poeta espanhol António Machado: "Caminante, no hay camino, se hace camino al andar".

Neste caminhar com o diferente enfrentamos nossas próprias resistências ao novo, ao diferente e ao complementar. As atividades transdsiciplinares revelam nossa dificuldade em enfrentar e lidar com o diverso. Acabamos reféns de atitudes e (pre)conceitos de que estamos no "Paradigma do Ou": ou é isso ou é aquilo...essa verdade ou aquela verdade... Mas, aos poucos percebemos que podemos escolher verdades que se complementam, e podemos então vivenciar o "Paradigma do E": pode ser isso e também aquilo...É preciso avançar em nossos obstáculos internos e externos: nossas atitudes, pensamentos e julgamentos limitados de uma realidade ilimitada e complexa. Essas são nossas prisões. E como tal precisam ser libertadas de nossos próprios muros, concepções enraizadas e cristalziadas da realidade que é mutante e em permanente evolução.

Faz-se claro que as contribuições da ecoformação e da transdisciplinaridade para a formação inicial de profesores assentaram-se na complementaridade dos opostos, contextualização dos conteúdos, princípio dialógico, recursão organizacional, flexibilidade e aceitação das diversidades e integração dos conteúdos.

A teoria traz em sua essência a Totalidade para a operacionalização, porém traz também o seu oposto complementar, a Incompletude. Esta como uma face aberta à renovação, pelo seu caráter processual e dinâmico, estará sempre construindo e se reconstruindo na prática. E esta será sempre parcial, particular e individual, mas pode se apresentar como referência para o coletivo de transformações que se busca, provocando e provocando-nos a qualificar o processo de formação de cada ser humano em direção à educação transformadora. 


\section{Referências}

Backes et al. (2011). Grupo focal como técnica de coleta e análise de dados em pesquisas qualitativas. O mundo da saúde, São Paulo, 35(4), 438-42.

Brasil. (1997). Secretaria de Educação Fundamental. Parâmetros curriculares nacionais: ciências naturais. Secretaria de Educação Fundamental. Brasília: MEC/SEF.

Bonil, J.; Calafell, G. (2008). Diálogo entre disciplinas na formação inicial de professores. In: . (Org.). Transdisciplinaridade e ecoformação: um novo olhar sobre a educação. São Paulo: TRIOM, pp. 322.

Chassot, A. (2011). Alfabetização científica: questões e desafios para a educação. 5. ed. Ijuí: Unijuí.

D’Ambrosio, U. (1997). Transdisciplinaridade. São Paulo: Palas Athena.

Delizoicov, D.; Angotti, J. A.; Pernambuco, M. M. ( 2011). Ensino de ciências: fundamentos e métodos. 4. ed. São Paulo: Cortez.

Demo, P. (2010). Educação e alfabetização científica. Campinas, SP: Papirus.

Freire, P.; Macedo, D. (1990). Alfabetização: leitura do mundo leitura da palavra. Rio de Janeiro: Paz e Terra.

Guevara, A. J. de H. et al.(1998). Conhecimento, cidadania e meio ambiente. São Paulo: Peirópolis.

Gutiérrez, F.; Prado, C. (2002). Ecopedagogia e cidadania planetária. São Paulo: Cortez.

Hernandez, F. (1998). Transgressão e Mudança na Educação: Os projetos de trabalho. Porto Alegre: Artmed.

Lervolino, S.A.; Pelicione, M.C.F. (2001,junho). A utilização do grupo focal como metodologia qualitativa na promoção da saúde. Rev. Esc. Enf. USP, 35(2), 115-21.

Lorenzetti, L., Delizoicov, D. (2001). Alfabetização científica no contexto das séries iniciais. Revista Ensaio, 03 (01).

Macedo, R. S. (2006). Etnopesquisa crítica, etnopesquisa-formação. Brasília: Líber Livro Editora.

Maturana, H.; Varela, F. (2010). A árvore do conhecimento: as bases biológicas da compreensão humana. 8 ed. Trad. Humberto Mariotti e Lia Diskin. São Paulo: Palas Athena.

Mensagem de Vila Velha e Vitória. II Congresso Mundial de Transdisciplinaridade. Brasil, Vila Velha e Vitória, 2005. Acesso em 20 de maio, 2013. Disponível em: http://www.cetrans.com.br/textos/documentos/mensagem-vila-velha-vitoria.pdf .

Moraes, M. C. (2008). Ecologia dos saberes: complexidade, transdisciplinaridade e educação: novos fundamentos para iluminar novas práticas educacionais. São Paulo: Antakarana/WHH - Willis Harman House. 
Morin, E. (2000). A cabeça bem feita: repensar a reforma, reformar o pensamento. Eloá Jacobina. Rio de Janeiro: Bertrand Brasil, 2000.

Nicolescu, B.(1999). O manifesto da transdisciplinaridade. São Paulo: Triom.

Nóvoa, A. (2009). Professores: imagens do futuro presente. Lisboa: EDUCA.

Pozo, J. I.; Crespo, M. A. G. (2009). A aprendizagem e o ensino de ciências: do conhecimento cotidiano ao conhecimento científico. 5. ed. Porto Alegre: Artmed.

Sá-Chaves, I. (2000). Portfólios Reflexivos: estratégia de formação e de supervisão. Aveiro: Ed. Universidade.

Santos, A.; Sommerman, A. (2009). Complexidade e transdisciplinaridade: em busca da totalidade perdida. Porto Alegre: Sulina.

Sousa Santos, B., Almeida, N. de, Filho. (2008). A universidade no século XXI: para uma universidade nova. Coimbra: Edições Almedina.

Silva, V. L. de S. (2004). Educar para a conexão: uma visão transdisciplinar de educação para a saúde integral. Blumenau: Nova Letra.

Severino, A. (2002). Educação e transdisciplinaridade: crise e reencantamento da aprendizagem. Rio de Janeiro: Lucerna.

SHORES, E.; GRACE, C. (2001). Manual de Portfólio: um guia passo a passo para o professor. Porto Alegre: Artmed.

TORRE, S. de La.; et al . (2008). Decálogo sobre transdisciplinaridade e ecoformação. In: . (Org.). Transdisciplinaridade e ecoformação: um novo olhar sobre a educação. São Paulo: TRIOM, pp. 21- 59.

Torre, S. De La.; Zwierewicz, M.; Furlanetto, E. C. (2011). Formação docente e pesquisa transdisciplinar: criar e inovar com outra consciência. In: DITTRICH, M.G. Um ponto de partida à transdisciplinaridade e à inovação no ensinar. Blumenau: Nova letra, p.99122.

Zwierewicz, M.; Torre, S. de La. Projetos criativos ecoformadores. (2009). In: . (Org.). Uma Escola para o Século XXI: escolas criativas e resiliência na educação. Florianópolis: Insular, pp. 153 - 175.

Ward, H. et al. (2010). Ensino de Ciências. 2. ed. Porto Alegre: Artmed.

Weil, P.; D’Ambrosio, U.; Crema, R. (1993). Rumo à nova transdisciplinaridade: sistemas abertos de conhecimento. São Paulo: Summus.

Wheatley, M.J. (2006). Liderança para tempos de incerteza: a descoberta de um novo caminho. Trad. Carlos Salum e Ana Franco. São Paulo: Cultrix. 